\title{
Potencial bioquímico de metano de la Chlorella vulgaris: influencia de la hidrólisis térmica
}

\section{Biochemical methane potential of Chlorella vulgaris: influence of thermal hydrolysis}

\section{Potencial bioquímico de metano da Chlorella vulgaris: Influência da hidrólise térmica}

\author{
Alexandra Cerón-Vivas ${ }^{1 *}$; Jessica Paola Acosta'; Lorraine Vanessa Alvear¹; Yolanda Gamarra ${ }^{1}$ \\ ${ }^{1}$ Facultad de Ingeniería Ambiental. Universidad Pontificia Bolivariana, km. 7 vía a Piedecuesta, Floridablanca, \\ Colombia. \\ *alexandra.ceron@upb.edu.co
}

\begin{abstract}
Resumen
La investigación sobre la transformación de biomasa en biocombustibles se ha incrementado en los últimos años. La digestión anaerobia es un proceso biológico en el cual el principal producto obtenido es biogás. La biomasa microalgal producida en plantas de tratamiento de aguas residuales puede ser usada como sustrato para la digestión anaerobia. Sin embargo, para mejorar la productividad de metano, es necesario el rompimiento de la pared celular de las microalgas por medio de pretratamientos. En este estudio, se evaluó la influencia de la hidrólisis térmica, como pretratamiento, sobre el potencial bioquímico de metano de la Chlorella vulgaris. Se determinaron las actividades de los diferentes grupos tróficos involucrados en el proceso anaerobio (hidrolítico, acidogénico y metanogénico), para evaluar la calidad del inóculo utilizado. La influencia de la hidrólisis térmica sobre la producción de metano fue evaluada aplicando el modelo modificado de Gompertz. Este modelo fue capaz de predecir la productividad final de metano para las microalgas cosechadas por centrifugación y para las sometidas a hidrólisis térmica. La tasa de producción máxima se incrementó de $18,4 \pm 1,0 \mathrm{ml} \cdot \mathrm{g}^{-1} \mathrm{SV} \cdot \mathrm{d}^{-1}$ a $29,0 \pm 3,1 \mathrm{ml} \cdot \mathrm{g}^{-1} \mathrm{SV} \cdot \mathrm{d}^{-1}$, cuando se aplicó la hidrólisis térmica a las microalgas. Este resultado puede asociarse con el rompimiento de la pared celular, que puede generar el incremento en la materia orgánica soluble y la producción de gas metano. Los resultados obtenidos sugieren que la hidrólisis térmica de la microalga $C$. vulgaris, puede ser utilizada como pretratamiento, para mejorar el rendimiento de la generación de metano, en la digestión anaerobia.
\end{abstract}

Palabras clave: microalgas, pretratamiento, digestión anaerobia, producción de metano

\begin{abstract}
Research on the biomass transformation into biofuels has increased in recent years. Anaerobic digestion is a biological process in which the main product obtained is biogas. Microalgal biomass produced in sewage treatment plants can be used as substrate for anaerobic digestion. However, to improve methane productivity, the breakdown of the microalgae cell wall through pre-treatments, is necessary. In this study, the influence of thermal hydrolysis, as pre-treatment, on biochemical methane potential of Chlorella vulgaris was assessed. Inoculum quality used was evaluated through the trophic groups' activities (hydrolytic, acidogenic and methanogenic). The influence of thermal hydrolysis on methane production was assessed applying the modified Gompertz model. This model was capable of predicting the final productivity of methane for the microalgae harvested by centrifugation and for those where thermal


hydrolysis was applied. The maximum production rate increased from $18,4 \pm 1,0 \mathrm{ml} \cdot \mathrm{g}^{-1} \mathrm{VS} \cdot \mathrm{d}^{-1}$ to $29,0 \pm 3,1$ $\mathrm{ml} \cdot \mathrm{g}^{-1} \mathrm{VS} \cdot \mathrm{d}^{-1}$, when thermal hydrolysis was applied to microalgae. This can be due to the breaking of the cell wall, resulting in increase in the soluble organic matter and the methane gas production. The results obtained suggest that the thermal hydrolysis of the $C$. vulgaris can be used as pre-treatment to improve the performance of methane generation in anaerobic digestion.

Keywords: microalgae, pre-treatment, anaerobic digestion, methane production

\begin{abstract}
Resumo
A investigação sobre a transformação de biomassa em biocombustíveis tem aumentado nos últimos anos. A digestão anaeróbia é um processo biológico em que o produto principal obtido é o biogás. Biomassa de microalgas produzido em plantas de tratamento de águas residuais pode ser utilizado como um substrato para a digestão anaeróbica. No entanto, para melhorar a produtividade de metano, que é necessário para quebrar a parede celular de microalgas utilizando pré-tratamentos. Assim, este estudo avaliou a influência da hidrólise térmica no potencial bioquímico de metano da Chlorella vulgaris. A qualidade do inóculo usado foi verificada avaliando a atividade de grupos tróficos (hidrolítica, acidogênica e metanogênica). A influência da hidrólise térmica na produção de metano foi avaliada aplicando o modelo modificado de Gompertz. Esse modelo foi capaz de prever a produtividade final para microalgas colhidas por centrifugação e para submetido a hidrólise térmica. A taxa máxima de produtividade aumentou de 18,4 $\pm 1,0 \mathrm{ml} \cdot \mathrm{g}^{-1} \mathrm{VS} . \mathrm{d}^{-1}$ a $29,0 \pm 3,1 \mathrm{ml} \mathrm{g}^{-1} \mathrm{VS}$. $\mathrm{d}^{-1}$, quando a hidrólise térmica foi aplicada às microalgas. Isso pode ser explicado devido ao rompimento da parede celular, resultando no aumento da matéria orgânica solúvel e produção do gás metano. Os resultados sugerem que a hidrólise térmica da C. vulgaris pode ser utilizado como pré-tratamento para melhorar o desempenho da geração de metano na digestão anaeróbica.
\end{abstract}

Palavras-chaves: microalga, pré-tratamento, digestão anaeróbica, produção de metano

\section{Introducción}

Las microalgas son organismos microscópicos fotosintéticos, capaces de transformar la energía luminosa en energía química, y se identifican como productores primarios de la cadena trófica. Tienen la capacidad de almacenar proteínas, carbohidratos, pigmentos, minerales, vitaminas y lípidos, los cuales son usados en diferentes aplicaciones. En las últimas décadas, las microalgas han logrado gran atención, gracias a su capacidad de remover nutrientes del agua residual $[1,2]$. La $C$. vulgaris ha sido considerada como una de las mejores microalgas para la biorremediación de aguas residuales, debido a su alto potencial para remover amonio y fósforo [3]

También han sido estudiadas ampliamente debido a su potencial de producción de biocombustibles, gracias a su elevado contenido de lípidos [4]. La producción de biodiésel, a partir de microalgas con concentraciones de lípidos elevadas y altas tasas de crecimiento, ha sido estudiada ampliamente $[2,3]$. Por el contrario, para la producción de bioetanol se usa biomasa microalgal con alto contenido de carbohidratos como materia prima $[4,7]$. Sin embargo, no se ha logrado que los sistemas duales de producción de algas que combinen tanto el tratamiento de aguas residuales como la producción de biodiésel sean sustentables económicamente [8].

Debido a la creciente necesidad de producir biocombustible y fuentes de energía, se ha venido generando un marcado interés en los procesos biológicos; la digestión anaerobia (DA) es uno de ellos. En la DA la materia orgánica, en ausencia de oxígeno, se descompone por la actividad metabólica de poblaciones bacterianas, para generar metano como producto principal. En la producción de metano, las bacterias hidrolíticas son las responsables de la conversión de sustratos orgánicos como lípidos, proteínas o carbohidratos en compuestos menos complejos. Los productos resultantes de la hidrólisis son fermentados, y se generan compuestos intermedios orgánicos como propionato, acetato, butirato, etc. Posteriormente, en la acidogénesis se produce acetato, $\mathrm{CO}_{2}$ y $\mathrm{H}_{2}$. En la etapa final, la actividad metabólica de los microorganismos metanógenos resulta en la generación de metano. Por lo anterior, el proceso anaerobio, al ser secuencial, depende de la etapa limitante y en gran parte del sustrato utilizado, 
ya que la biodegradabilidad anaerobia difiere de acuerdo con su composición química.

Las microalgas han sido utilizadas como sustrato en procesos de DA, mezclándose con residuos agropecuarios, domésticos y algunos industriales, lo que ha mostrado un incremento en la producción de metano. Las principales ventajas de usar microalgas como sustrato en digestión anaerobia son: (1) se pueden usar directamente después de cosecharlas; (2) pueden ser usadas después del proceso de extracción de lípidos [9], y (3) el líquido digerido puede ser usado como fertilizante, debido a su alto contenido de nutrientes.

El potencial bioquímico de metano (PBM) de las microalgas varía desde 120 hasta $590 \mathrm{ml} / \mathrm{g} \mathrm{SV}$, dependiendo de la especie y las condiciones de cultivo [10]. Sin embargo, este puede ser afectado por la estructura compleja de la pared celular. La Chlorella vulgaris es una microalga que tiene una pared celular resistente al ataque de los microorganismos en la digestión anaerobia [3]; por tanto, la aplicación de tratamientos previos para romper la pared celular de las microalgas y liberar su contenido intracelular es crucial para mejorar la digestión de las microalgas y la producción de metano [11].

Para mejorar la digestión anaerobia de las microalgas, se han utilizado procesos físicos y químicos como microondas, tratamiento térmico, ultrasonido y tratamiento biológico con enzimas [10-12]. El ultrasonido mejora la ruptura de la pared celular de las microalgas, pero la eficiencia depende de la energía de sonicación específica y el tipo de sustrato usado. El tratamiento con enzimas puede convertir los biopolímeros de la pared celular en compuestos de bajo peso molecular, los cuales son más accesibles para los microorganismos anaeróbicos [15].

En la hidrólisis térmica, se combina la aplicación de alta presión y temperatura a la biomasa microalgal, para causar destrucción de la pared celular, lo que permite que el contenido intracelular sea más accesible para los microorganismos anaerobios, y se mejora la productividad de metano. El objetivo de este estudio fue evaluar la influencia de la hidrólisis térmica como pretratamiento sobre el potencial bioquímico de metano (PBM) de la $C$. vulgaris.

\section{Metodología}

\section{Sustrato y pretratamiento}

El sustrato utilizado para las pruebas de potencial bioquímico de metano fue un cultivo de $C$. vulgaris suministrado por el Laboratorio de Biomasa de la Universidad Industrial de Santander. Las microalgas fueron cultivadas en botellas Schott de 2 I con medio de cultivo Bold Basal (BB) [16]. Se utilizó un módulo de cultivo con lámparas fluorescentes a 4700 lux, fotoperiodos de 12 horas luz/oscuridad a temperatura ambiente (22-26 $\left.{ }^{\circ} \mathrm{C}\right)$. Se acopló un dispositivo de desgasificación, que permitía la liberación de oxígeno durante el proceso de fotosíntesis. La agitación en el reactor y el suministro del $\mathrm{CO}_{2}$ requerido por las microalgas se realizó por medio de burbujeo, a través de un sistema de inyección de aire. El aire inyectado fue filtrado a través de filtros Pall Acro 50 de 0,2 micras, para retener material particulado, con el fin de evitar la contaminación del reactor. Las microalgas fueron recolectadas periódicamente y concentradas por centrifugación (HERMLE, Z206A) a $5000 \mathrm{rpm}$ por $10 \mathrm{~min}$.

La hidrólisis térmica $(\mathrm{HT})$ fue utilizada como pretratamiento para mejorar la digestión anaerobia de la biomasa microalgal. Una fracción de microalga centrifugada (MC) fue llevada a la autoclave (Sturdy, SA-300VL) por 15 minutos a $100{ }^{\circ} \mathrm{C}$ y $104 \mathrm{kPa}$. Las microalgas concentradas y pretratadas (MHT) fueron almacenadas en botellas ámbar de $500 \mathrm{ml} \mathrm{a} 4{ }^{\circ} \mathrm{C}$ para la evaluación del PBM.

\section{Inóculo}

El inóculo utilizado para las pruebas de PBM fue lodo anaerobio de un reactor UASB de una industria de bebidas gaseosas, el cual fue caracterizado con los siguientes parámetros fisicoquímicos: sólidos volátiles totales (SVT), sólidos totales (ST), sólidos suspendidos volátiles (SSV), sólidos suspendidos totales (SST), $\mathrm{pH}$, ácidos grasos volátiles totales (AGVT) y alcalinidad, de acuerdo con los protocolos estándar [17]. Adicionalmente, se realizaron pruebas de actividad acidogénica (AA), hidrolítica $(A H)$ y metanogénica específica (AME) al inóculo.

Para las pruebas de $\mathrm{AA}$ y $\mathrm{AH}$ se utilizó como sustrato glucosa y almidón, respectivamente, con una concentración de $0,15 \mathrm{gDQO} \cdot \mathrm{L}^{-1}$. Las pruebas fueron realizadas usando botellas ámbar de 120 
$\mathrm{ml}$ con $100 \mathrm{ml}$ de volumen útil, las cuales fueron llenadas con inóculo $\left(1,5 \mathrm{gSSV} \cdot \mathrm{L}^{-1}\right)$ y sustrato. En todos los experimentos (AA y $\mathrm{AH}$ ) fueron adicionados macronutrientes, micronutrientes, solución de sulfuro, extracto de levadura y bicarbonato, de acuerdo con Field [18], y fueron incubados a $37^{\circ} \mathrm{C}$.

Se tomaron muestras del sobrenadante para determinar las concentraciones remanentes de glucosa o almidón en las botellas. La periodicidad del muestreo fue de tres horas durante dos días, y cada seis horas, hasta completar la prueba. La concentración de glucosa fue medida como la concentración de azúcares reductores, y la de almidón, como la diferencia entre azúcares totales y reductores. Los azúcares reductores fueron determinados de acuerdo con el método del DNS [19] y los azúcares totales con el método de Dubois [20]. La AA y AH fueron calculadas con la ecuación 1 , donde $P$ es la máxima pendiente de consumo, $F C$ es el factor de conversión (gDQO $\cdot g$ ${ }^{1}$ glucosa), $V$ y gSSV son el volumen de inóculo y la masa adicionada [21].

$$
A=P \times F C \times \frac{V_{\text {Inóculo }}}{g S S V_{\text {Inóculo }}} \times 24
$$

Tabla 1. Soluciones usadas en pruebas anaerobias.

\begin{tabular}{|c|c|c|}
\hline Solución & Reactivo & Concentración $\left(g \cdot \mathrm{L}^{-1}\right)$ \\
\hline \multirow[t]{4}{*}{ Macro-nutrientes } & $\mathrm{NH}_{4} \mathrm{Cl}$ & 170,00 \\
\hline & $\mathrm{KH}_{2} \mathrm{PO}_{4}$ & 37,00 \\
\hline & $\mathrm{CaCl}_{2} \cdot 2 \mathrm{H}_{2} \mathrm{O}$ & 8,00 \\
\hline & $\mathrm{MgSO}_{4} \cdot 7 \mathrm{H}_{2} \mathrm{O}$ & 11,56 \\
\hline \multirow[t]{11}{*}{ Micro nutrientes } & $\mathrm{FeCl}_{3} \cdot 6 \mathrm{H}_{2} \mathrm{O}$ & 2,71 \\
\hline & $\mathrm{CoCl}_{2} \cdot 6 \mathrm{H}_{2} \mathrm{O}$ & 2,00 \\
\hline & $\mathrm{MnCl}_{2} \cdot 2 \mathrm{H}_{2} \mathrm{O}$ & 0,41 \\
\hline & $\mathrm{CuCl}_{2} \cdot 2 \mathrm{H}_{2} \mathrm{O}$ & 0,03 \\
\hline & $\mathrm{ZnSO}_{4} \cdot 7 \mathrm{H}_{2} \mathrm{O}$ & 0,11 \\
\hline & $\mathrm{H}_{3} \mathrm{BO}_{3}$ & 0,05 \\
\hline & $\left(\mathrm{NH}_{4}\right)_{6} \mathrm{Mo}_{7} \mathrm{O}_{24} \cdot 4 \mathrm{H}_{2} \mathrm{O}$ & 0,09 \\
\hline & $\mathrm{Na}_{2} \mathrm{SeO}_{3} \cdot 5 \mathrm{H}_{2} \mathrm{O}$ & 0,10 \\
\hline & EDTA & 1,00 \\
\hline & $\mathrm{HCl}$ & $1 \mathrm{~mL}$ \\
\hline & Resazurin & 0,50 \\
\hline Sulfuro & $\mathrm{Na}_{2} \mathrm{~S} \cdot 10 \mathrm{H}_{2} \mathrm{O}$ & 107,50 \\
\hline Extracto de levadura & & 20 \\
\hline Bicarbonato & $\mathrm{NaHCO}_{3}$ & 15 \\
\hline
\end{tabular}

Fuente: [18]

Para la AME se utilizó como sustrato una solución compuesta de ácido acético, propiónico y butírico, de acuerdo con las recomendaciones hechas por Field [18]. Las pruebas se realizaron usando un sistema Oxitop ${ }^{\circledR}$ (WTW Germany) con botellas de vidrio de $500 \mathrm{ml}$ de capacidad y volumen útil de $400 \mathrm{ml}$. La concentración de inóculo utilizada fue de $1,5 \mathrm{gSSV} / \mathrm{L}$, debido a que el ensayo se realizó con agitación intermitente (3 veces al día) [18]. En todos los experimentos se adicionaron las soluciones mostradas en la tabla 1.
Finalmente, se realizó burbujeo con gas nitrógeno durante tres minutos, para mantener las condiciones anaerobias y se colocaron perlas de $\mathrm{NaOH}$ en un soporte plástico dentro de las botellas del Oxitop, para absorber el dióxido de carbono del biogás. Las botellas fueron incubadas en un baño de agua a $37^{\circ} \mathrm{C}$, y se realizó agitación manual (tres veces al día). La producción de biogás fue medida como el incremento en la presión cada dos horas durante la primera semana, y gradualmente disminuyó hasta el final de la prueba. La presión medida por el 
cabezal fue convertida en producción volumétrica de metano acumulada con la ecuación 2.

$$
V_{C_{4}} C E=\frac{\Delta P \times V_{i} \times T_{C E}}{P_{C E} \times T e} \times 1000
$$

Donde

$V_{C H 4} C E=$ volumen de metano a condiciones estándar $(\mathrm{mL})$

$\Delta P=$ diferencia de presión (atm)

$V_{i}=$ volumen libre $(\mathrm{L})$

$T_{C E}=$ temperatura a condiciones estándar $(\mathrm{K})$

$P_{C E}=$ presión a condiciones estándar (atm)

$T_{e}=$ temperatura del experimento $(\mathrm{K})$

La AME fue calculada con la máxima pendiente de la curva de producción de metano acumulado $(\mathrm{ml} \cdot \mathrm{d}$ ${ }^{1}$ ), dividido por la cantidad de SSV introducida en la botella, usando el factor de conversión apropiado para reportarla como $\mathrm{gDQO} \cdot \mathrm{g}^{-1} \mathrm{SSV} \cdot \mathrm{d}^{-1}$.

\section{Potencial bioquímico de metano}

Los ensayos de PBM fueron realizados de la misma manera que la $\mathrm{AME}$, utilizando como sustrato las microalgas centrifugadas y pretratadas. Se adicionó una cantidad de sustrato tal que la relación sustrato/inóculo (S/I) fuera de 0,5 gDQO/ gSV [12]. El PBM fue calculado por la ecuación 3 , donde $V_{T C H 4}$ es el volumen de metano (L) y $g S V$ son los sólidos volátiles del sustrato.

$$
P B M=\frac{V_{T_{C H}}}{g S V}
$$

Las pruebas se llevaron a cabo por duplicado para las algas centrifugadas (MC) y las algas pretratadas (MHT). Se realizó una prueba de referencia del inóculo, sin sustrato, para medir la cantidad de metano producida. El PBM de las microalgas centrifugadas y pretratadas fue calculado como la diferencia entre los resultados de PBM de cada corrida y la prueba de referencia (figura 1).
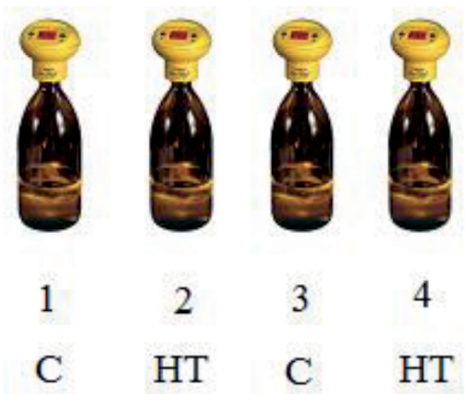

Figura 1. Montaje experimental

La influencia de la HT sobre la producción de metano fue evaluada aplicando el modelo modificado de Gompertz (ecuación 4) descrito por Zwietering et al. [22]Gompertz, Richards, Schnute, and Stannard y Lay et al. [23], donde $M\left(\mathrm{~mL} \cdot \mathrm{g}^{-1} \mathrm{SV}\right)$ es la producción de metano obtenida en el tiempo $t, P\left(\mathrm{~mL} \cdot \mathrm{g}^{-1} \mathrm{SV}\right)$ es la producción acumulada de metano al final de la prueba, $R_{\max }$ es la tasa de producción máxima de metano $\left(\mathrm{mL} \cdot \mathrm{g}^{-1} \mathrm{SV} \mathrm{d}^{-1}\right)$, $\lambda=$ duración de la fase de latencia (d) y e es la constante matemática $(2,718)$. Además, a partir del primer día de medición, se calcularon las tasas de producción de metano $(\mathrm{Rg})$ para intervalos de tres días con la ecuación 5 , donde $M_{i}\left(\mathrm{~mL} \cdot \mathrm{g}^{-1} \mathrm{SV}\right)$ es la producción de metano obtenida en el tiempo $\mathrm{i}, t_{i}$, y $M_{i-3}\left(\mathrm{~mL} \cdot \mathrm{g}^{-1} \mathrm{SV}\right)$ es la producción de metano obtenida en el tiempo i-3, $t_{i-3}$.

$$
\begin{gathered}
M=P \exp \left[-\exp \left\{\frac{R_{\max } e}{P}(\lambda-t)+1\right\}\right] \\
R_{g}=\frac{M_{i}-M_{i-3}}{t_{i}-t_{i-3}}
\end{gathered}
$$

\section{Resultados y discusión}

\section{Caracterización del inóculo}

La tabla 2 muestra los resultados de la caracterización fisicoquímica del inóculo. La relación SSVISST muestra la presencia de biomasa activa útil para la degradación de la materia orgánica. El valor típico de esta relación es de 0,7, indicando que el inóculo utilizado fue adecuado para el arranque del proceso 
de digestión anaerobia [24]. El pH del inóculo garantizó la actividad de las poblaciones bacterianas durante el proceso de DA, al encontrarse dentro del rango de 6,8 y 7,5 [25]. La alcalinidad representa la capacidad buffer y evita la acidificación del sistema, cuando su valor es superior a $1,5 \mathrm{~g} / \mathrm{L} \mathrm{CaCO}_{3}$ [26]. De acuerdo con los resultados, el inóculo utilizado tiene buena capacidad buffer, lo que garantizó el buen funcionamiento del digestor, al amortiguar los cambios de $\mathrm{pH}$ debido a la generación de AGV en el proceso.

Para determinar la actividad acidogénica e hidrolítica del inóculo, se analizó el consumo de almidón y glucosa durante 120 horas, respectivamente. La tasa máxima de consumo de almidón estuvo entre las cero y 12 horas, dando como resultado una $\mathrm{AH}$ de 2,06 gDQO $\mathrm{gSSV}^{-1} \mathrm{~d}^{-1}$, reflejando capacidad del inóculo para degradar el sustrato usado, a través de la actividad enzimática [27]000ha of fique fields (Furcraea sp., family Agavaceae. Para la glucosa, la tasa máxima de consumo estuvo entre las cero y seis horas, y la AA fue $3,05 \mathrm{gDQO} \cdot \mathrm{gSSV}^{-1} \mathrm{~d}^{-1}$. Las actividades hidrolíticas y metanogénica dependen del tipo de biomasa, sustrato o condiciones de operación. Los valores de AA y AH encontrados en el presente trabajo son similares a los obtenidos para un lodo proveniente de la industria azucarera [28].

Tabla 2. Caracterización fisicoquímica del inóculo

\begin{tabular}{ccc}
\hline Parámetro & Unidades & Valor \\
\hline ST & $\mathrm{g} \cdot \mathrm{L}^{-1}$ & 32,02 \\
SVT & $\mathrm{g} \cdot \mathrm{L}^{-1}$ & 29,40 \\
SST & $\mathrm{g} \cdot \mathrm{L}^{-1}$ & 30,20 \\
SSV & $\mathrm{g} \cdot \mathrm{L}^{-1}$ & 28,29 \\
$\mathrm{SSV} / \mathrm{SST}$ & & 0,94 \\
$\mathrm{pH}$ & Units & 7,10 \\
Alcalinidad & $\mathrm{mg} \mathrm{CaCO} \cdot \mathrm{L}^{-1}$ & 1787,50 \\
AGVT & $\mathrm{meq} \cdot \mathrm{L}^{-1}$ & 0,0013 \\
\hline
\end{tabular}

La producción acumulada de metano alcanzada con el inóculo (figura 2) corresponde a una AME de $0,124 \mathrm{gDQO}_{\mathrm{CH} 4} \cdot \mathrm{gSSV}^{-1} \mathrm{~d}^{-1}$, encontrándose en el rango recomendado para lodos digeridos e indicando su potencial uso como inóculo [29]. Comparando los valores de $\mathrm{AA}$ y $\mathrm{AH}$, estos fueron más altos que los de la AME. La AA es usualmente mayor que la actividad metanogénica, debido a que el proceso se realiza primero y su producto (acetato) es usado durante la metanogénesis [30]. Los valores de las actividades hidrolítica y acidogénica son similares a los reportados por Poirrer (AA: 3,7 gDQO/gSSV.d; AH: 2,26 gDQO/gSSV.d) para un lodo anaerobio procedente de reactor UASB de industria papelera [21]; sin embargo, la AME obtenida en ese estudio fue mayor $\left(0,47 \mathrm{gDQOCH}_{4} / \mathrm{gSSV}\right.$.d). De acuerdo con Soto et al. [31], la AME depende de las características del lodo, el tipo de sustrato, las condiciones ambientales y el procedimiento de la prueba. Adicionalmente, reportan que la AME es más baja que la $\mathrm{AA}$ y la $\mathrm{AH}$ cuando el sustrato usado es soluble. Lo anterior concuerda con los resultados obtenidos, teniendo en cuenta que el lodo utilizado proviene de un reactor anaerobio que trata aguas residuales provenientes de una industria de bebidas azucaradas.

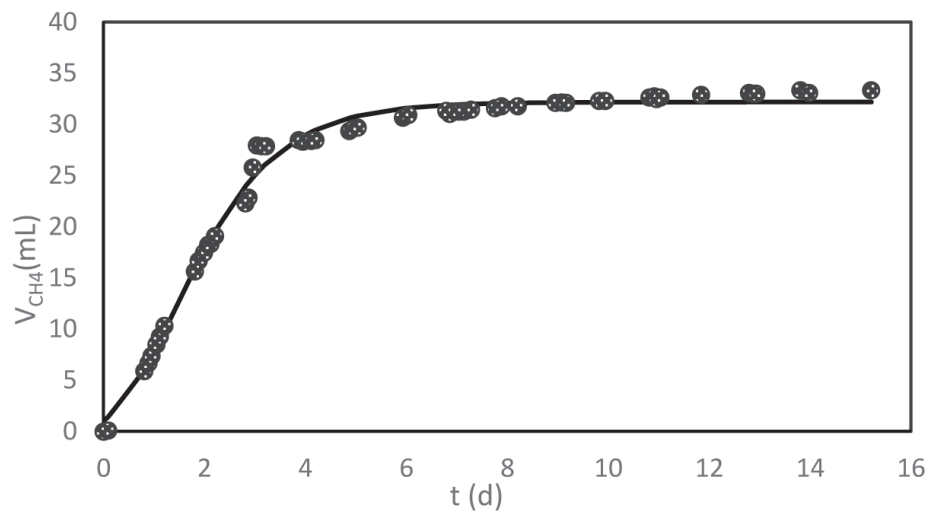

Figura 2. Producción acumulada de metano obtenida con el inóculo en la $A M E$ 


\section{Potencial bioquímico de metano}

La (figura 3) muestra la producción acumulada de metano alcanzada por las microalgas centrifugadas y pretratadas durante 15 días. La producción de metano comenzó con un periodo de adaptación aproximadamente de un día en todos los reactores. Durante los siguientes seis días de incubación, la productividad en $\mathrm{C}$ y HT se incrementó linealmente y posteriormente disminuyó de forma gradual.

La HT rompe la pared celular y libera el contenido intracelular, quedando disponible para la degradación biológica y así mejorar el proceso de digestión anaerobia [10]. En este estudio, el pretratamiento incrementó en un $42,6 \%$ la producción máxima de metano $\left(0,179 \pm 0,025 \mathrm{LCH}_{4} \cdot \mathrm{gSV}^{-1}\right)$, con respecto a la obtenida por las microalgas centrifugadas $(0,129$ $\left.\pm 0,020 \mathrm{LCH}_{4} \cdot \mathrm{gSV}^{-1}\right)$; sin embargo, no existen diferencias significativas entre las dos condiciones experimentales $(p>0,05 ; p=0,06)$. Los resultados de este estudio coinciden con los obtenidos por Passos y Ferrer [32] quienes encontraron que la producción de metano incrementó de 0,12 a 0,15 y $0,17 \mathrm{LCH}_{4} \cdot \mathrm{gSV}^{-1}(25 \%)$ en las microalgas pretratadas a $110^{\circ} \mathrm{C}$ y $130^{\circ} \mathrm{C}$, respectivamente. No obstante, valores superiores han sido reportados para diferentes microalgas o mezcla de estas. Cho et al. [33] utilizaron una mezcla de Chlorella sp. y Scenedsmus sp., pretratada a $120^{\circ} \mathrm{C}$, como sustrato para digestión anaerobia. Ellos alcanzaron una producción de metano de $0,4 \mathrm{LCH}_{4} \cdot \mathrm{gSV}^{-1}$ para las algas pretratadas, la cual fue un $20 \%$ más alta que la obtenida sin pretratamiento. Igualmente, Alzate et al. [12] encontraron valores de PBM entre $0,30 \mathrm{~L} \mathrm{CH}_{4} / \mathrm{gSV}$ y $0,40 \mathrm{~L} \mathrm{CH}_{4} / \mathrm{gSV}$ para mezcla de microalgas pretratadas a $170{ }^{\circ} \mathrm{C}$.

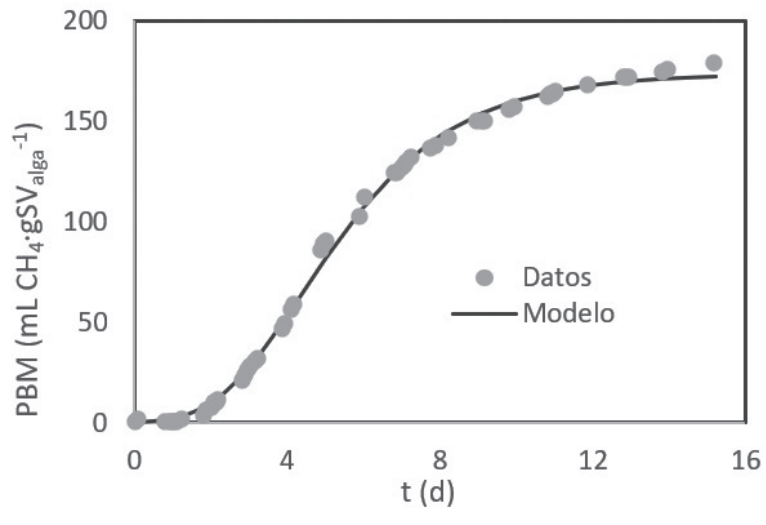

(a)

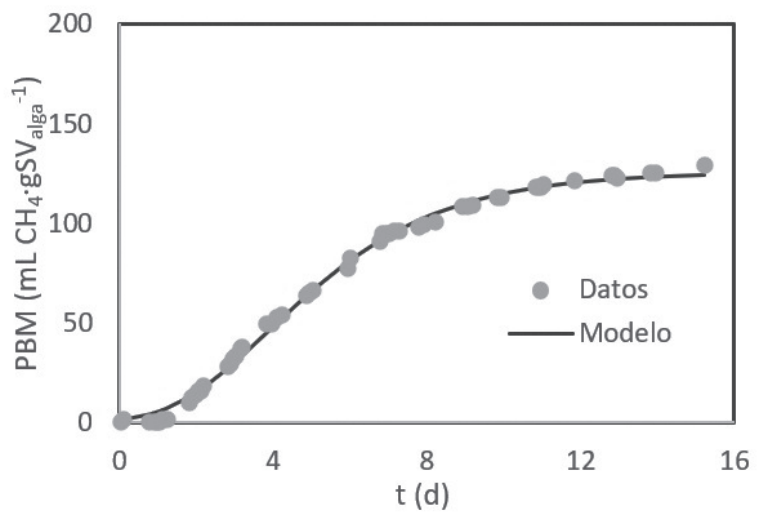

(b)

Figura 3. Modelo modificado de Gompertz ajustado con los datos experimentales para HT (a) y C (b).

Para predecir el efecto de la hidrólisis térmica de las microalgas sobre la producción acumulada de metano, se utilizó el modelo de Gompertz modificado. Los valores de $R^{2}>0,99$ demostraron que la ecuación 4 fue adecuada para describir el progreso de la producción acumulada de metano de las microalgas pretratadas (figura 3). Las constantes cinéticas $P, \lambda$ y $R_{\max }$ fueron estimadas por una regresión lineal y sus valores son mostrados en la tabla 3. La producción máxima acumulada de metano alcanzada con este modelo $(P)$ fue similar a la obtenida experimentalmente. La tasa máxima de producción $\left(R_{\max }\right)$ aumentó de $18,4 \pm 1,0 \mathrm{ml} \cdot \mathrm{g}^{-1} \mathrm{SV} \cdot \mathrm{d}^{-1}$ a $29,0 \pm 3,1 \mathrm{ml} \cdot \mathrm{g}^{-1} \mathrm{SV} \cdot \mathrm{d}^{-1}$, cuando se aplicó $\mathrm{HT}$ a las microalgas. Este incremento posiblemente se debió al daño de la pared celular de las microalgas, lo que incrementó la materia orgánica soluble, la cual mejoró la producción de metano.

Tabla 3. Parámetros cinéticos del modelo de Gompertz obtenidos

\begin{tabular}{cccc}
\hline & $\mathbf{P}$ & $\mathbf{R}_{\max }$ & $\boldsymbol{\Lambda}$ \\
\hline TH & $173,6 \pm 13,8$ & $29,0 \pm 3,1$ & $2,1 \pm 0,5$ \\
C & $125,6 \pm 12,7$ & $18,4 \pm 1,0$ & $1,4 \pm 0,3$ \\
\hline
\end{tabular}


La (figura 4) muestra las tasas de producción de metano $(\mathrm{Rg})$, calculadas para intervalos de tres días. Los máximos valores de $\mathrm{Rg}$ obtenidos para HT y C fueron 28,1 y $17,2 \mathrm{ml} \mathrm{CH}_{4} \cdot \mathrm{gSV}^{-1} \cdot \mathrm{d}^{-1}$, respectivamente. En todos los intervalos, los valores de Rg fueron más altos para HT, excepto en las primeras tres horas. Estos valores son superiores a los reportados por Prajapati et al. [11], quienes calcularon $\mathrm{Rg}$ en intervalos de 5 días para C. minutissima $\left(15,80 \pm 0,57 \mathrm{mLCH}_{4} \cdot \mathrm{gSV}^{-1} \cdot \mathrm{d}^{-1}\right), C$. pyrenoidosa $\left(22,06 \pm 1,16 \mathrm{mLCH}_{4} \cdot \mathrm{gSV}^{-1} \cdot \mathrm{d}^{-1}\right)$ y $C$. vulgaris $\left(18,68 \pm 0,54 \mathrm{mLCH}_{4} \cdot \mathrm{gSV}^{-1} \cdot \mathrm{d}^{-1}\right)$. Aunque las tasas de producción de metano obtenidas en este estudio fueron más altas que las reportadas por Prajapati et al. [11], la producción acumulada de metano alcanzada por las microalgas centrifugadas y pretratadas fue más baja. Los valores de $\mathrm{Rg}$ obtenidos confirman que la tasa máxima de producción de metano para las algas centrifugadas se obtuvo en los primeros tres días y luego disminuyó gradualmente, mientras que las algas sometidas a hidrólisis térmica presentaron algún tipo de inhibición en los primeros días, que causó un incremento en su fase de latencia, como se observa en la Tabla 3. Sin embargo, a partir del cuarto día la tasa de producción incrementa hasta alcanzar el valor máximo en el día 6. La inhibición para las microalgas sometidas a HT en los primeros días de experimentación puede asociarse al cambio en las características de las células, debido al daño causado en la estructura celular por el pretratamiento. Passos et al. [34] reportaron que algunos pretratamientos realizados a las microalgas no logran romper la pared celular, pero sí dañan la estructura celular de esta, lo cual puede cambiar las características de las células. Por otro lado, aunque el pretratamiento no haya logrado romper la pared celular, sí la puede dejar más susceptible al ataque celular, lo cual pudo permitir que, pasada la fase de latencia, se incrementara la biodegradabilidad anaerobia, lo que se reflejó en mayores tasas de producción de metano.

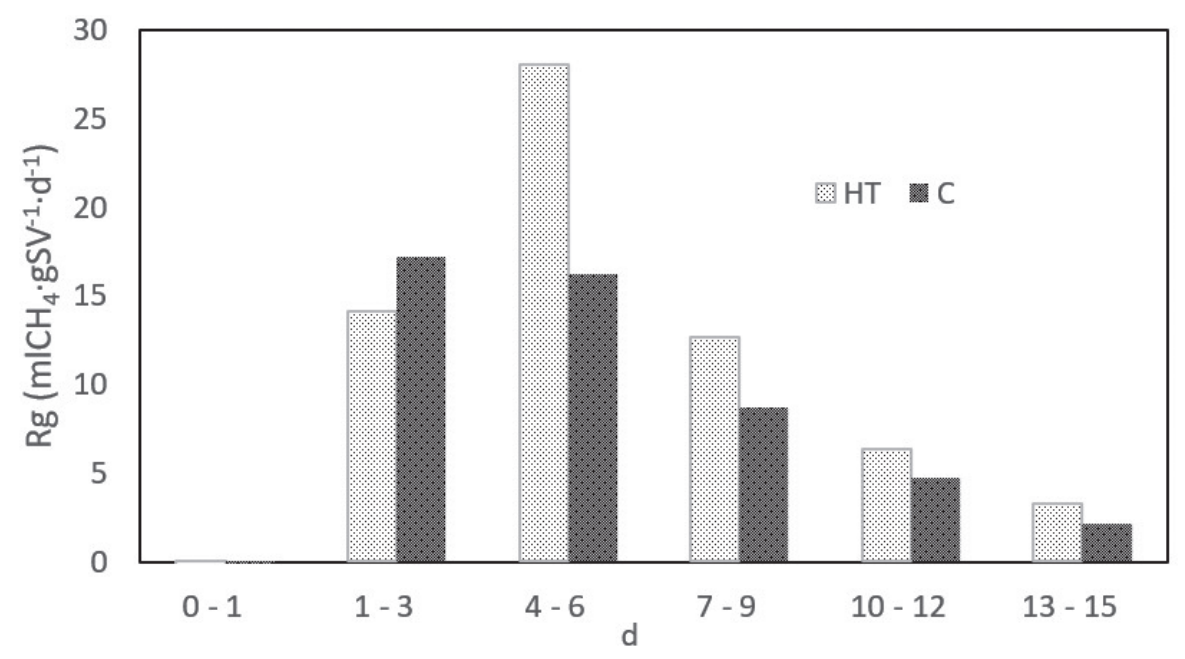

Figura 4. Tasa de producción de metano para intervalos de tres días.

\section{Conclusiones}

Uno de los mayores inconvenientes para la producción de metano a partir de microalgas es la degradación de la pared celular. En este estudio, la hidrólisis térmica aplicada a la microalga $C$. vulgaris antes del proceso de digestión anaerobia permitió un incremento del $39 \%$ en la producción acumulada de metano $\left(0,179 \pm 0,252 \mathrm{~L} \mathrm{CH}_{4} \cdot \mathrm{gSV}^{-1}\right)$, en comparación con la obtenida por microalgas centrifugadas $\left(0,129 \pm 0.020 \mathrm{~L} \mathrm{CH}_{4} \cdot \mathrm{gVS}^{-1}\right)$. Sin embargo, no existen diferencias significativas entre las dos condiciones experimentales, por lo que es necesario investigar otras alternativas de pretratamiento.

El modelo de Gompertz fue adecuado para describir el progreso de la producción acumulada de metano de las microalgas pretratadas y centrifugadas. La tasa de producción máxima de metano (Rmax) obtenida en las pruebas de PBM, para las microalgas sometidas a hidrólisis térmica, fue un $56 \%$ superior a la alcanzada por las microalgas centrifugadas, debido probablemente a la liberación de material interno como consecuencia del daño en la pared celular. 


\section{Agradecimientos}

El Proyecto número 052-0614-2400 fue financiado por la Dirección de Investigaciones y Transferencia de la Universidad Pontificia Bolivariana.

\section{Referencias bibliográficas}

[1] Aslan S, Kapdan IK. Batch kinetics of nitrogen and phosphorus removal from synthetic wastewater by algae. Ecol Eng [Internet]. 2006 Nov [cited 2014 Jul 15];28(1):64-70. Available from: http://linkinghub.elsevier.com/retrieve/ pii/S0925857406000759

[2] Cai T, Park SY, Li Y. Nutrient recovery from wastewater streams by microalgae: Status and prospects. Renew Sustain Energy Rev [Internet]. 2013 Mar [cited 2014 Jul 14];19:3609. Available from: http://linkinghub.elsevier. com/retrieve/pii/S1364032112006429

[3] Safi C, Zebib B, Merah O, Pontalier P-Y, Vaca-Garcia C. Morphology, composition, production, processing and applications of Chlorella vulgaris: A review. Renew Sustain Energy Rev. 2014;35:265-78.

[4] Singh J, Gu S. Commercialization potential of microalgae for biofuels production. Renew Sustain Energy Rev. 2010;14(9):2596-610.

[5] Chisti Y. Biodiesel from microalgae beats bioethanol. Trends Biotechnol. 2008;26:12631.

[6] Mubarak M, Shaija A, Suchithra T V. Review on the extraction of lipid from microalgae for biodiesel production. Algal Res. 2015;7:11723.

[7] Harun R, Danquah MK. Enzymatic hydrolysis of microalgal biomass for bioethanol production. Chem Eng J. 2011;168(3):1079-84.

[8] Lundquist IW. A realistic technology and engineering assessment of algae biofuel production. 2010.

[9] Alzate ME, Muñoz R, Rogalla F, Fdz-Polanco F, Pérez-Elvira SI. Biochemical methane potential of microalgae biomass after lipid extraction. Chem Eng J. 2014;243:405-10.

[10]Prajapati SK, Kaushik P, Malik A, Vijay VK. Phycoremediation coupled production of algal biomass, harvesting and anaerobic digestion: possibilities and challenges. Biotechnol Adv. 2013;31(8):1408-25.

[11] Prajapati SK, Malik A, Vijay VK. Comparative evaluation of biomass production and bioenergy generation potential of Chlorella spp. through anaerobic digestion. Appl Energy. 2014;114:790-7.

[12] Alzate ME, Muñoz R, Rogalla F, Fdz-Polanco F, Pérez-elvira SI. Biochemical methane potential of microalgae : Influence of substrate to inoculum ratio, biomass concentration and pretreatment. Bioresour Technol. 2012;123:488-94.

[13] González-Fernández C, Sialve B, Bernet N, Steyer JP. Comparison of ultrasound and thermal pretreatment of Scenedesmus biomass on methane production. Bioresour Technol. 2012;110:610-6.

[14]Passos F, Solé M, García J, Ferrer I. Biogas production from microalgae grown in wastewater: Effect of microwave pretreatment. Appl Energy. 2013;108:168-75.

[15] Klassen V, Blifernez-klassen $O$, Wobbe L, Schlüter A, Kruse O, Mussgnug JH. Efficiency and biotechnological aspects of biogas production from microalgal substrates. J Biotechnol. 2016;234:7-26.

[16]Bischoff H., Bold HC. Phycological studies IV. In: Some soil algae from Enchanted Rock and related algal species. Austin: University of Texas; 1963. p. 1-95.

[17]APHA, AWWA, WEF. Standard Methods for the Examination of Water and Wastewater. 22th editi. Washington DC.; 2012.

[18] Field J. Parametros operativos del manto de lodos anaeróbicos de flujo ascendente. In: Manual de Arranque y operación de flujo ascendente con manto de lodos - UASB. Cali: Universidad del Valle, CVC. Universidad Agrícola de Wageningen.; 1987. p. 270.

[19] Miller GL. Use of Dinitrosalicylic Acid Reagent for Determination of Reducing Sugar. Anal Chem. 1953;31(3):426-8.

[20]Dubois M, Pilles K, Hamilton J, Smith F. Colorimetric method for determination of sugar and related substances. Anal Chem. 1956;28:350-6.

[21] Poirrier González P. Hidrólisis y acidificación psicrófila de moléculas complejas en sistemas anaerobios. Santiago de Compostela, España: Universidad de Santiago de Compostela; 2005.

[22]Zwietering $\mathrm{MH}$, Jongenburger I, Rombouts FM, Van't Riet K. Modeling of the bacterial growth curve. Appl Environ Microbiol. 1990;56(6):1875-81.

[23] Jiunn-Jyi L, Yu-You L, Noike T. Influences of $\mathrm{pH}$ and moisture content on the methane 
production in high-solids sludge digestion. Water Res. 1997;31(6):1518-24.

[24] Castro Echavez FL, Fernández Acosta NM, Delgado Chávez MJ. Disminución de la DQO en aguas de formación utilizando cepas bacterianas. Rev Técnica la Fac Ing Univ del Zulia. 2008;31(3):246-55.

[25] Herrera Soracá DM, Niño Bonilla DA. Evaluación del potencial producción de biogas a partir de aguas residuales provenientes de la industria palmera mediante la digestión anaerobia. Universidad Industrial de Santander; 2011.

[26] Instituto para la Diversificación y Ahorro de la Energía - IDAE. Biomasa: Digestores Anaerobios. [Internet]. Madrid, España: Instituto para la Diversificación y Ahorro de la Energía; 2007. 48 p. Available from: http://www.idae. es/uploads/documentos/documentos_10737_ Biomasa_digestores_07_a996b846.pdf

[27] Quintero M, Castro L, Ortiz C, Guzmán $\mathrm{C}$, Escalante $\mathrm{H}$. Enhancement of starting up anaerobic digestion of lignocellulosic substrate: Fique's bagasse as an example. Bioresour Technol. 2012;108:8-13.

[28]Regueiro L, Veiga P, Figueroa M, AlonsoGutierrez J, Stams AJM, Lema JM, et al. Relationship between microbial activity and microbial community structure in six fullscale anaerobic digesters. Microbiol Res. 2012;167(10):581-9.

[29]Díaz-Báez MC, Vargas SLE, Pérez FM.
Digestión anaerobia: una aproximacion a la tecnología. First. Bogotá D.C., Colombia: Universidad Nacional de Colombia; 2002. 168 p.

[30]Effebi KR, Baya T, Jupsin H, Vasel JL. Acidogenic and Methanogenic activities in Anaerobic Ponds. 2011;2(12):1-4.

[31] Soto M, Méndez R, Lema JM. Methanogenic and non-methanogenic activity tests. Theoretical basis and experimental set up. Water Res [Internet]. 1993 Aug [cited 2015 Sep 7];27(8):1361-76. Available from: http:// www.sciencedirect.com/science/article/ pii/0043135493902246

[32] Passos F, Ferrer I. Influence of hydrothermal pretreatment on microalgal biomass anaerobic digestion and bioenergy production. Water Res [Internet]. 2014;68:364-73. Available from: http://dx.doi.org/10.1016/j.watres.2014.10.015

[33] Cho S, Park S, Seon J, Yu J, Lee T. Evaluation of thermal, ultrasonic and alkali pretreatments on mixed-microalgal biomass to enhance anaerobic methane production. Bioresour Technol [Internet]. 2013 Sep [cited 2014 Jul 17];143:330-6. Available from: http://www. ncbi.nlm.nih.gov/pubmed/23811066

[34]Passos F, Ferrer I. Microalgae Conversion to Biogas: Thermal Pretreatment Contribution on Net Energy Production. Environ Sci Technol [Internet]. 2014 Jun 17;48(12):71718. Available from: https://doi.org/10.1021/ es500982v 